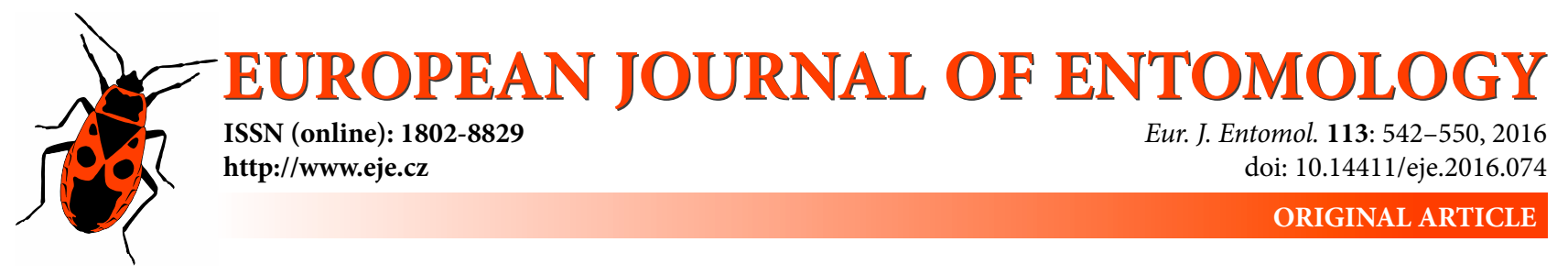

\title{
Females of the parasitoid wasp, Dendrocerus carpenteri (Hymenoptera: Megaspilidae), adjust offspring sex allocation when competing for hosts
}

\author{
MANFred MACKAUER and Andrew CHOW* \\ Department of Biological Sciences, Simon Fraser University, 8888 University Drive, Burnaby, BC V5A 1S6, Canada; \\ e-mail: mackauer@sfu.ca
}

\begin{abstract}
Key words. Megaspilidae, Dendrocerus carpenteri, competition, hyperparasitoid, larval mortality, intensity of parasitism, offspring sex allocation, sex ratio, superparasitism
\end{abstract}

\begin{abstract}
Parasitoid females may adjust offspring sex allocation according to the number and quality of hosts available. Because in solitary species only one offspring survives per host, already parasitized hosts are of low quality and generally rejected. Superparasitism (i.e., sequential oviposition by the same or different females) results in aggressive interactions and competition for nutritional resources among larvae. We examined variations in the offspring sex ratio of Dendrocerus carpenteri (Curtis) (Hymenoptera: Megaspilidae), a solitary ectoparasitoid developing as a hyperparasitoid on the prepupae and pupae of primary aphid parasitoids inside mummified aphids. Mated females produced a female-biased sex ratio of 0.433 (proportion of sons) when caged singly and provided with 12 mummies for $2 \mathrm{~h}$; they parasitized an average of four mummies/h and rarely superparasitized. Superparasitism increased when two females were caged together and provided with 12 mummies, from 1.18 to 1.24 and 1.38 eggs/host parasitized in 1, 2 and $3 \mathrm{~h}$, respectively. The offspring sex ratio became increasingly more female-biased with increase in superparasitism; however, sex ratio variations were not correlated with cohort size. One mated and one unmated female provided with 12 mummies and caged together for $1 \mathrm{~h}$ produced a mean cohort sex ratio of 0.645 , which differed from the one predicted $(0.717)$ by an algebraic model incorporating the assumptions that both females contribute equal numbers of offspring and that the mated female does not change her offspring-sex allocation strategy. The observed shift in the cohort sex ratio to an increased female-bias indicates that mated females of $D$. carpenteri change their behaviour when encountering parasitized mummies or a conspecific competitor in the same patch. By depositing fertilized rather than unfertilized eggs, a female can increase the proportion of her daughters among parasitoids competing for a diminishing host supply.
\end{abstract}

\section{INTRODUCTION}

Superparasitism by parasitoid wasps occurs when the host is parasitized repeatedly by the same or different females, with one or several eggs being laid per oviposition bout. Superparasitism may result in offspring mortality and in the loss of search time and resources invested by the female in egg production and oviposition (van Alphen \& Visser, 1990; Godfray, 1994; Dorn \& Beckage, 2007). The modalities of larval interactions determining winners and losers in such contests depend on the lifestyle of the species involved, the number and specific identity of the superparasitizing female(s) and the sex and age of competing larvae, among other factors (Mackauer, 1990; Brodeur \& Boivin, 2004; Harvey et al., 2013). Superparasitism has different consequences in solitary and gregarious parasitoids. Solitary species generally respond to superparasitism by lethal combat between first instars or by physiological suppression resulting in the death of all but one larva, but facultative gregarious development is observed in several species (Nostvik, 1954; Mayhew \& van Alphen, 1999; Riddick, 2002; Mackauer \& Chow, 2012, 2015). Survival in contests between conspecific larvae is determined by the age or developmental stage of the immature parasitoids, with the first-hatched larva typically having an age advantage over younger competitors (Mackauer, 1990; van Baaren et al., 1999; Darrouzet et al., 2008; Harvey et al., 2013). Gregarious species, in contrast, do not fight for host possession but eliminate supernumerary larvae by scramble competition for limiting host resources $(\mathrm{Gu}$ et al., 2003; Brodeur \& Boivin, 2004; Shuker et al., 2005; Dorn \& Beckage, 2007). Thus, sequential oviposition by a second (i.e., superparasitizing) female will only result in offspring mortality if the available host resources are insufficient to sustain the development of all the immatures. Aggressive interactions causing mortality may also occur between older larvae in both solitary (Ito \& Yamada, 2014)

\footnotetext{
* Current address: Texas A\&M University-Kingsville, Citrus Center, 312 N. International Blvd, Weslaco, TX 78599, USA; e-mail: Andrew.Chow@tamuk.edu
} 
and gregarious parasitoids (Tena et al., 2009, 2011). Both self- and conspecific superparasitism occur when several females of one species exploit a diminishing host supply.

Superparasitism can affect and potentially bias the offspring sex ratio at emergence (King, 1993; Godfray, 1994). Immature survival may be sex-specific if male and female larvae have different nutritional requirements or if one sex is a better competitor than the other (Ode et al., 1996; van Baaren et al., 1999; Sykes et al., 2007; Kapranas et al., 2011). In addition, a female may alter her offspring sex-allocation strategy if she encounters parasitized hosts (Werren, 1984; Shuker et al., 2005; Diaz-Fleischer et al., 2015) or other females searching the same patch (Wylie, 1979; Visser, 1995; Ito \& Yamada, 2016). For example, van Baaren et al. (1999) reported that superparasitizing females of Anaphes victus Huber (Hymenoptera: Mymaridae), a solitary egg parasitoid, produced a more male-biased sex ratio than females attacking unparasitized eggs; however, the sex ratio at eclosion was unchanged because male larvae suffered proportionately higher mortality than their female counterparts. In contrast, in Eupelmus vuilleti (Crawford) (Hymenoptera: Eupelmidae), a solitary ectoparasitoid of bruchid larvae and pupae, the sex ratio became more female-biased with increasing self-superparasitism, possibly due to a proportionately higher male mortality (Darrouzet et al., 2003); but Darrouzet et al. (2008) were unable to confirm sex-specific immature mortality. Females of Echthrodelphax fairchildii Perkins (Hymenoptera: Dryinidae) normally deposit a single egg under the right or left wing bud of plant hopper nymphs (Ito \& Yamada, 2014). Mated females allocate offspring sex according to host size, depositing fertilized eggs on the larger fifth-instar nymphs and unfertilized eggs on the smaller third- and fourth-instar nymphs; however, after encountering a conspecific, females increasingly laid fertilized eggs resulting in both self- and conspecific superparasitism (Ito \& Yamada, 2016). Montoya et al. (2011) and DiazFleischer et al. (2015) observed an increasingly femalebiased sex ratio with higher levels of superparasitism in mass-reared Diachasmimorpha longicaudata (Ashmead) (Hymenoptera: Braconidae) attacking fruit fly larvae, a result confirmed by field collections of infested mango fruits (Montoya et al., 2013). In contrast, in many gregarious parasitoids, superparasitizing females produce a relatively more male-biased sex ratio as predicted by models of local mate competition (Wylie, 1965; Suzuki \& Iwasa, 1980; Suzuki et al., 1984; Godfray, 1994; West, 2009).

Models of offspring and offspring sex allocation by parasitoid wasps assume that females modify their behaviour in accordance with changed environmental conditions if the gains in fitness are greater than the costs of the change (West, 2009). Variations in the mean sex ratio produced by two or more (mated and unmated) females searching for hosts in the same patch can result from either a change in the proportion of offspring contributed by individual females without a change in offspring sex allocation, or a change in offspring sex allocation without a change in the contribution of individual females, or a combination of both. Female larvae often do less well in suboptimal hosts than their male counterparts because of their greater and/or different nutritional requirements (Mackauer et al., 1997; Otto \& Mackauer, 1998; Ellers et al., 2001). Therefore, host-quality models predict that mothers should deposit unfertilized eggs in low-quality and fertilized eggs in high-quality hosts (King, 1993; Godfray, 1994). Host quality is not absolute but relative, depending on the kinds of host available and the female's physiological state (van den Assem, 1971; Cloutier et al., 1991; Mackauer et al., 1996). Having encountered an already parasitized host, a female may place a higher value on the next host she finds, regardless of its quality, and deposit a fertilized egg (van den Assem, 1971; Cloutier et al., 1991) or superparasitize it if her offspring is likely to survive larval competition (Mackauer et al., 1992; Visser et al., 1990, 1992; Lebreton et al., 2009). Increased superparasitism can also be induced by pre-experiment experience, for example, when females are kept in groups (Visser et al., 1990).

This study examines the oviposition behaviour of Dendrocerus carpenteri (Curtis) (Hymenoptera: Megaspilidae), a solitary ectoparasitoid developing as a hyperparasitoid on the prepupae and pupae of various aphidiine (Hymenoptera: Braconidae: Aphidiinae) parasitoids inside mummified aphids (Bocchino \& Sullivan, 1981; Walker \& Cameron, 1981; Chow \& Mackauer, 1999a,b). Females probe the aphid mummy with their ovipositor and normally deposit a single egg either directly on the host or inside the mummy shell. Chow \& Mackauer (1996) showed that mated females fertilized the first egg when encountering a high-quality host but laid an unfertilized egg if the host was of low quality. The sex of the second egg laid in a sequence was generally opposite that of the first; however, with each additional egg, females laid relatively more fertilized eggs if host quality was high and relatively more unfertilized eggs if host quality was low. Females rejected parasitized mummies, which were marked externally, but they readily superparasitized them after being deprived of hosts for a time. Newly hatched first instars are aggressive and search for potential competitors within the mummy shell; any eggs and larvae encountered are attacked and killed. Occasionally more than one larva survives competition in superparasitized mummies, with up to three offspring developing in a single mummy (Mackauer \& Chow, 2015). The larva feeds externally on the host which is envenomed by the female at oviposition; the venom causes developmental arrest in the primary parasitoid at the prepupal stage. Females are relatively long-lived but average daily fecundity is low, ranging between six and 15 hosts parasitized (Walker \& Cameron, 1981; Chow, 2000).

Mated females of $D$. carpenteri provided with unparasitized hosts normally produce a balanced or slightly female-biased offspring sex ratio (Chow \& Mackauer, 1996). However, Mackauer \& Chow (2015) noted that the sex ratio becomes more female-biased under conditions resulting in competition for hosts and superparasitism. To assess the influence of superparasitism on the oviposition behaviour of $D$. carpenteri, we tested the hypothesis that 
mated females caged singly and counterparts caged together with a second mated or unmated female would deposit the same number of eggs and produce the same number of offspring per unit of search time and number of hosts available. Next, we estimated immature mortality among singly developing offspring by comparing the proportion of parasitized mummies as determined by dissection with the proportion of mummies from which adult wasps emerged. In addition, we assessed sex-specific immature mortality by comparing the distribution of offspring sexes emerging from gregarious mummies (i.e., facultative gregarious development) with their binomial expectations. And last, we tested the hypothesis that mated females of $D$. carpenteri competing for hosts changed their offspring-sex allocation behaviour and selectively laid fertilized eggs. Because we could not determine the sex and parentage of eggs or larvae, we compared the observed offspring sex ratio with the one predicted by an algebraic model if one female is unmated and constrained to produce only sons from unfertilized eggs while the second female is mated and can produce both daughters from fertilized eggs and sons from unfertilized eggs.

\section{MATERIALS AND METHODS}

\section{General methods}

We established a colony of $D$. carpenteri with specimens eclosing from pea-aphid mummies, Acyrthosiphon pisum (Harris) (Hemiptera: Aphidoidea: Aphididae), collected in alfalfa fields near Kamloops, British Columbia $\left(50.40^{\circ} \mathrm{N}, 120.19^{\circ} \mathrm{W}\right)$; the mummies contained prepupae and pupae of the primary parasitoid Aphidius ervi Haliday (Hymenoptera: Braconidae: Aphidiinae). In the laboratory, $D$. carpenteri was reared on the same host system, except that pea aphids were reared on potted broad beans, Vicia faba $\mathrm{L}$. cv "Broad Windsor" (Leguminosae), rather than alfalfa. All insect colonies were maintained in growth chambers at $20 \pm 0.5^{\circ} \mathrm{C}$, $50-70 \% \mathrm{RH}$, and continuous light. To avoid possible bias due to variations in host quality, both pea aphids and $A$. ervi were standardized by age. Pea aphids were $48 \pm 4$ h old (i.e., second instar) at the time of parasitization by A. ervi, and A. ervi was $9 \pm 0.5 \mathrm{~d}$ old (i.e., prepupa) at the time of hyperparasitization by $D$. carpenteri. Because the experiments required a large number of mummies and parasitoids, 5-6 females of $A$. ervi were confined with 100-200 aphids in a plastic petri dish. After $2 \mathrm{~h}$, the aphids were transferred to bean plants and reared until parasitized individuals died and mummified. When the primary parasitoids were $9 \mathrm{~d}$ old, 8-10 D. carpenteri females were caged together with 200-300 mummies in a screened plastic container. The females were removed after $24 \mathrm{~h}$, and the mummies stored at $20^{\circ} \mathrm{C}$ in a growth chamber. Eclosing D. carpenteri were collected every $24 \mathrm{~h}$ at the same time and kept as cohorts comprising about 15-20 males and females each; females from these cohorts were assumed to have mated. Virgin females were obtained from mummies placed singly in $20 \times 8 \mathrm{~mm}$ clear gelatine capsules; single mummies were treated in the same manner as mummies kept in groups. All females of $D$. carpenteri used in experiments were 9-10 d old and, presumably, contained a large number (ca. 15-20) of mature eggs in the ovaries (Otto \& Mackauer, 1998). To ensure that females would not dump eggs on the first host encountered in a trial, we provided each female with three mummies, one at a time, immediately prior to testing. Chow \& Mackauer (1999b) reported that host-deprived females of $D$. carpenteri laid an average of 3.50 , 1.67 and 1.17 eggs, respectively, on the first, second and third host encountered; however, they laid only one egg on any hosts encountered subsequently. Offspring emerging from these mummies were used to verify the mating status of all females used in the experiments. Females, from cohorts with males, which failed to produce at least one daughter, were assumed not to have mated, and the results of trials including such females were excluded from the subsequent evaluation (see below).

We set up five experiments consisting of replicated trials (Table 1). Each trial included 12 hosts (i.e., mummies containing a prepupa of $A$. ervi), which were arranged in a $3 \times 4$ square matrix and glued with honey to a piece of white cardboard placed in a $5 \mathrm{~cm}$ diameter petri dish. The experiments were designed to determine the influence of the mother's mating status (mated vs. unmated) on offspring number and sex ratio when caged singly and when competing with a conspecific female searching the same patch under increasing superparasitism. First, we tested the hypothesis that mated and unmated females lay eggs at the same rate, i.e., mated and unmated females produce the same number of offspring under similar conditions. The number of hosts available was the same in experiments 1,2 and 5, namely six mummies per female per $1 \mathrm{~h}$ of search time. Specifically, in experiment 1 , mated females were caged singly for $2 \mathrm{~h}$ while in experiments 2 and 5 , two females were caged together for $1 \mathrm{~h}$, one mated female with another mated and unmated female, respectively. Second, we determined the influence of superparasitism on offspring number and offspring sex allocation when two mated females were caged together for increasing periods (experiments 2, 3 and 4). And third, in experiment 5, we assessed the interactions between one mated and one unmated female caged together for 1 $h$. Trials in each experiment were arbitrarily assigned to one of two subsets: Mummies in the first subset were placed individually into gelatine capsules, coded for each trial and experiment, and reared until parasitoid emergence: experiment 1 (46 trials), 2 (30 trials), 3 (30 trials), 4 (30 trials) and 5 (30 trials). Emerged parasitoids were counted by sex. All mummies in the second subset were dissected in order to estimate parasitism: experiment 1 (25 trials), 2 (12 trials), 3 (11 trials) and 4 (11 trials). Superparasitism was measured as the mean intensity of parasitism, i.e., the mean number of eggs and larvae found in parasitized hosts, pooled between trials within experiments. We use the term cohort to refer to the total number of offspring produced in each trial, regardless of the number of females used; the cohort sex ratio is given as the proportion of sons among all offspring.

\section{Offspring sex allocation}

Because we could not distinguish between the offspring of two different females developing as a cohort, we assessed offspring sex allocation by comparing the proportion of sons among offspring produced by mated females caged singly with the proportion of sons among offspring produced by one mated female caged together with another mated or virgin female. If both mated and unmated females deposit the same number of eggs per unit of search time and number of hosts available, any difference in the cohort sex ratio between a mated female and an unmated female competing for hosts and the sex ratio when females are not competing signifies a change in offspring sex allocation by the mated female. We used an algebraic model to explore the relationship between the number of eggs deposited per unit of search time by one mated female and one unmated female competing for hosts and the proportion of eggs fertilized by the mated female.

Consider two females, A and B, simultaneously exploiting the same patch and competing for hosts for their offspring. Female $\mathrm{A}$ is unmated and constrained to lay only unfertilized eggs whereas female B has mated and can lay both unfertilized and fertilized eggs. The model incorporates the following assump- 
tions: (1) Females discriminate between parasitized and unparasitized hosts but cannot distinguish self-parasitized hosts from those parasitized by a conspecific female. (2) In the absence of unparasitized hosts, already parasitized hosts will be attacked repeatedly by one or both females, which results in superparasitism; the order of attack(s) by females A and B is random. (3) Singly-parasitized hosts are of equal quality for male and female offspring. (4) Both females contribute equally to the total number of offspring produced. And (5), developmental mortality among same-aged offspring is random with regard to sex and oviposition sequence.

Let $n_{A}$ and $n_{B}$ be the number of offspring produced by females $\mathrm{A}$ and $\mathrm{B}$ and $\mathrm{r}=\mathrm{n}_{\mathrm{A}} / \mathrm{N}$ and $(1-\mathrm{r})=\mathrm{n}_{\mathrm{B}} / \mathrm{N}$ be the proportion of the total number of offspring, $\mathrm{N}=\mathrm{n}_{\mathrm{A}}+\mathrm{n}_{\mathrm{B}}$, contributed by each female, respectively. The sex ratio $\mathrm{p}$ is determined by the proportion of unfertilized eggs among all eggs laid by each female. For the constrained female $A, p_{A}=1$. For the mated female $B, p_{B}$ can vary between 0 (i.e., all eggs fertilized) and 1 (i.e., all eggs unfertilized). If immature mortality is random with regard to offspring sex (assumption 5), the cohort sex ratio is given by $\mathrm{p}_{\mathrm{N}}$, which is the proportion of sons among all offspring:

$\mathrm{p}_{\mathrm{N}}=\frac{\left(\mathrm{N} \cdot \mathrm{r} \cdot \mathrm{p}_{\mathrm{A}}\right)+\left(\mathrm{N} \cdot(1-\mathrm{r}) \cdot \mathrm{p}_{\mathrm{B}}\right)}{\mathrm{N}}=\mathrm{r}+(1-\mathrm{r}) \cdot \mathrm{p}_{\mathrm{B}}$

If both females contribute equally to the total number of offspring (assumption 4), $r=0.5$, equation (1) reduces to:

$\mathrm{p}_{\mathrm{N}}=1 / 2 \cdot\left(1+\mathrm{p}_{\mathrm{B}}\right)$

Assumptions (1) and (2) are well supported by empirical evidence for D. carpenteri (Chow \& Mackauer, 1996) and other parasitoid Hymenoptera (Godfray, 1994). However, assumption (3) is made to simplify the analysis but does not hold in general (Mackauer \& Lardner, 1995; Otto \& Mackauer, 1998) while assumptions (4) and (5) are lacking empirical support.

We tested assumption 4 that a female's oviposition rate does not vary with her mating status and the presence of other females by comparing the number of eggs laid by singly-caged mated females (experiment 1 ) with the total number laid by two mated females caged together (experiment 2). In addition, we compared the number of offspring produced by one or two mated females (experiments 1 and 2) with the number of offspring produced by one mated and one virgin female caged together (experiment 5). In all three experiments, females were provided with the same number of hosts per $1 \mathrm{~h}$ of search time, i.e., six mummies.

We tested assumption 5 that immature mortality is random with regard to offspring sex by comparing the observed frequencies of "double" mummies yielding two males, one male plus one female, and two females with their binomial expectations. We used the mean sex ratio of singly parasitized hosts as an estimate of the probability that a second egg will not be fertilized, assuming that a superparasitizing female of $D$. carpenteri can discriminate between unparasitized and already parasitized hosts (Chow \& Mackauer, 1999a) but has only incomplete information about the number and sex of any egg(s) already present. Therefore, a female's decision of fertilizing an egg or not should be independent of the sex of previously deposited eggs but may vary with host quality and egg value. A significant difference between the observed and expected frequencies of offspring sexes within classes of "double" mummies indicates that the risk of immature mortality differs between offspring sexes or, alternatively, that fertilization of a later-deposited egg in a sequence is not independent of the sex of the egg(s) already present.

\section{Influence of superparasitism}

In experiments 2, 3 and 4 , the search time increased from $1 \mathrm{~h}$ to $3 \mathrm{~h}$ while the number of hosts available to two females exploiting the same host patch was kept the same (Table 1). Because of developmental variation, any age advantage among the offspring of sequentially attacking females can be largely ignored for age differences of $\leq 3 \mathrm{~h}$ (Chow \& Mackauer, 1999a). We compared the cohort sex ratios between the three experiments in order to test the hypothesis that the offspring sex allocation strategy of mated females does not vary with the intensity of parasitism; the sex ratio obtained in experiment 1 served as a control.

\section{Data analysis}

Because of the large number of trials involved, the experiments were done over several days with insects from the same source colonies and reared under the same conditions. The mean sex ratio is given as the proportion of sons among offspring pooled between trials within experiments. Experiments were analyzed separately. We compared the mean cohort sizes and the angular transformed cohort sex ratios using 1-way ANOVA. Because ANOVA indicated significant heterogeneity among the means, we used the Tukey-Kramer procedure for unplanned comparisons (Sokal \& Rohlf, 1995, p. 500) to determine the statistical significance $(\mathrm{P} \leq 0.05)$ of differences between the means. We calculated the $95 \%$ confidence intervals (CI) of proportions using the modified Wald method (Agresti \& Coull, 1998). We used the log-likelihood ratio $(\mathrm{G})$ test with Williams' correction to compare the distribution of offspring sexes over gregarious mummies with their binomial expectations (Sokal \& Rohlf, 1995, p. 699). Probabilities from independent tests of significance were combined with Fisher's method (Sokal \& Rohlf, 1995, p. 794). We used a package in the Free Statistics Software program (Wessa, 2012) to calculate Kendall's tau. The $95 \%$ CI of the mean intensity of parasitism was estimated by the bootstrap method in the Quantitative Parasitology 3.0 program (Rózsa et al., 2000). All probabilities are 2-tailed.

Table 1. Intensity of parasitism and sex ratio among offspring of Dendrocerus carpenteri parasitizing pupae of Aphidius ervi inside mummified pea aphids, Acyrthosiphon pisum (see Materials and Methods for details).

\begin{tabular}{|c|c|c|c|c|c|c|c|c|}
\hline \multirow{2}{*}{$\begin{array}{l}\text { Expt } \\
\text { No. }\end{array}$} & \multirow{2}{*}{$\begin{array}{l}\text { No. females } \\
\text { caged }^{1}\end{array}$} & \multirow{2}{*}{$\begin{array}{l}\text { No. hosts } \\
\text { available }^{2}\end{array}$} & \multirow{2}{*}{$\begin{array}{c}\text { Sample } \\
\text { size }^{3}\end{array}$} & \multirow{2}{*}{$\begin{array}{c}\text { Cohort size } \\
\text { Mean }^{6} \pm \text { SEM }\end{array}$} & \multicolumn{2}{|c|}{ Sex ratio $^{4}$} & \multicolumn{2}{|c|}{ Intensity of parasitism ${ }^{5}$} \\
\hline & & & & & Mean $^{6}$ & $(95 \% \mathrm{Cl})$ & Mean & $(95 \% \mathrm{Cl})$ \\
\hline 1 & $1(2 \mathrm{~h})$ & 6 & 46 & $8.13 \pm 0.34^{a}$ & $0.433^{a}$ & $(0.384-0.484)$ & 1.06 & $(1.02-1.09)$ \\
\hline 2 & $2(1 \mathrm{~h})$ & 6 & 30 & $8.07 \pm 0.46^{a}$ & $0.430^{\mathrm{a}}$ & $(0.369-0.493)$ & 1.18 & $(1.10-1.27)$ \\
\hline 3 & $2(2 \mathrm{~h})$ & 3 & 30 & $10.60 \pm 0.33^{b}$ & $0.374^{a, b}$ & $(0.323-0.429)$ & 1.24 & $(1.16-1.32)$ \\
\hline 4 & $2(3 \mathrm{~h})$ & 2 & 30 & $11.60 \pm 0.25^{b}$ & $0.328^{b}$ & $(0.280-0.379)$ & 1.38 & $(1.27-1.50)$ \\
\hline 5 & $2(1 \mathrm{~h})$ & 6 & 30 & $8.57 \pm 0.45^{a}$ & & & & \\
\hline
\end{tabular}

${ }^{1}$ All females were mated except those used in experiment 5 , which latter included one mated and one unmated female; the time females were caged together is given in brackets. ${ }^{2}$ All trials included 12 mummies; the number of hosts available is given as the number of mummies per female per $1 \mathrm{~h}$ of search time. ${ }^{3}$ Sample size is the number of replicated trials. ${ }^{4}$ The mean sex ratio $\left(p_{N}\right)$ is given as the proportion of males among offspring pooled among trials. ${ }^{5}$ The mean intensity of parasitism is measured as the mean number of parasitoid eggs and larvae per parasitized host as determined by dissection (see General Methods for sample sizes). ${ }^{6}$ Means sharing the same letter(s) are not significantly different $(P>0.05)$. 


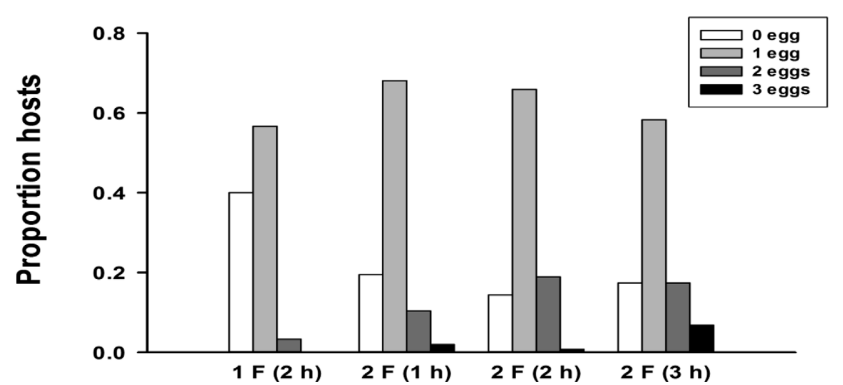

Fig. 1. The distribution of parasitoid eggs among hosts by mated females of Dendrocerus carpenteri. Females were provided with 12 mummies of Aphidius ervi for different periods. Abbreviations: 1 $\mathrm{F}(2 \mathrm{~h})=$ one female caged for $2 \mathrm{~h} ; 2 \mathrm{~F}(1 \mathrm{~h} ; 2 \mathrm{~h} ; 3 \mathrm{~h})=$ two females caged together for $1 \mathrm{~h}, 2 \mathrm{~h}$ and $3 \mathrm{~h}$, respectively.

\section{RESULTS}

\section{Cohort size}

The mean number of offspring produced by mated females caged singly for $2 \mathrm{~h}$ (experiment 1 ) did not significantly differ from the number produced by one mated female caged for $1 \mathrm{~h}$ together with a second mated (experiment 2) or virgin female (experiment 5) (1-way ANOVA: $\left.F_{2,103}=0.398 ; P=0.67\right)$ (Table 1$)$. The overall mean estimated from the pooled data was 8.24 offspring $(\mathrm{SEM}=$ $0.23 ; \mathrm{n}=106$ ) or $4.1 \mathrm{offspring} /$ female/h of search time. Cohort size increased with search time in experiments 1-5 (1-way ANOVA: $F_{4,161}=17.902 ; P<0.001$ ) (Table 1 ).

Fig. 1 shows the distribution of parasitoid eggs among hosts by mated females. Singly caged females laid an average of 1.06 eggs on each host parasitized and rarely selfsuperparasitized (experiment 1). In contrast, when two mated females competed for the same number of hosts per unit of search time, they laid an average of 1.18 eggs per host parasitized, of which $15.5 \%$ were superparasitized

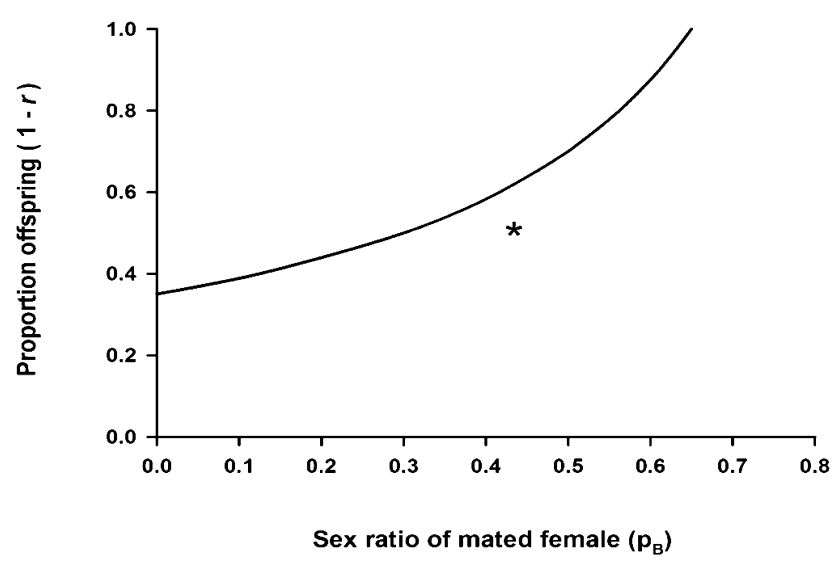

Fig. 2. The influence of variations in offspring number and offspring sex allocation on the observed sex ratio $\left(p_{N}=0.645\right)$ among offspring produced by one mated and one unmated female of Dendrocerus carpenteri caged together and provided with 12 mummies of Aphidius ervi for $1 \mathrm{~h}$. The line shows different combinations of the sex ratio of the mated female $\left(p_{B}\right)$ and her contribution to cohort size $(1-r)$ yielding a sex ratio of $p_{N}=0.645$, as predicted by equation 1 . The asterisk indicates the expected cohort sex ratio $\left(p_{N}=0.717\right)$ if both females contribute equally to the total number of offspring $(1-r=0.5)$ and the mated female does not modify her offspring sex allocation $\left(p_{B}=0.433\right)$ in the presence of a conspecific competitor (see text for details).

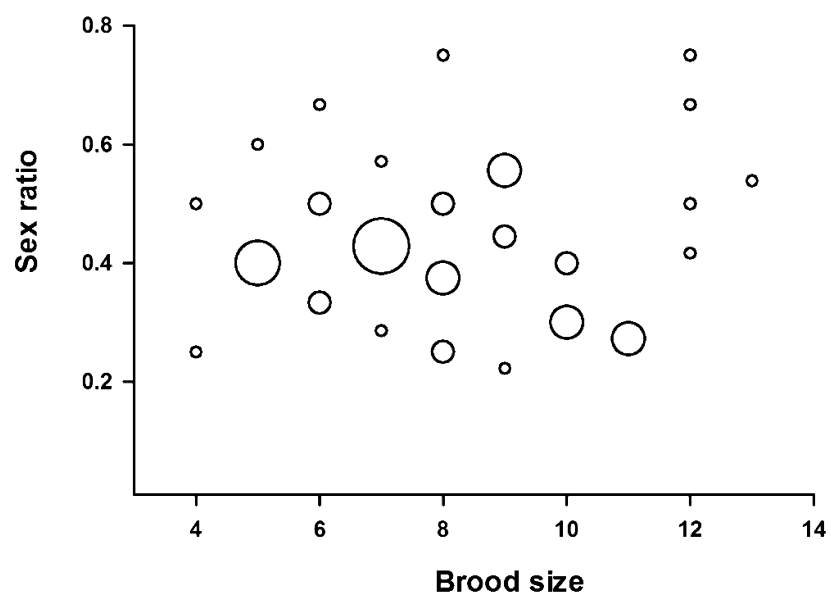

Fig. 3. The offspring number and offspring sex ratio produced by mated females of Dendrocerus carpenteri $(n=46)$ provided with 12 mummies of Aphidius ervi for $2 \mathrm{~h}$. The diameter of the dots is weighted by the number of same-sized cohorts containing the same proportions of male and female offspring.

(experiment 2). The mean intensity of parasitism as well as the proportion of parasitized hosts increased with the length of the confinement period, although between $14 \%$ and $19 \%$ of the available mummies were not parasitized (Table 1).

\section{Immature mortality}

Mated females of $D$. carpenteri caged singly for $2 \mathrm{~h}$ (experiment 1) parasitized $60 \%$ of the available mummies (n $=300$ ) as determined by mummy dissection. This result did not differ from the percentage of mummies parasitized $(66.5 \% ; \mathrm{n}=552)$ as determined by rearing (Fisher's exact test: $\left.P_{\alpha(2)}=0.06\right)$. However, the percentage of dissected aphids that were superparasitized $(5.6 \% ; n=180)($ Fig. 1) was significantly greater than the percentage of mummies from which more than one wasp emerged $(1.9 \% ; n=367)$ (Fisher's exact test: $P_{\alpha(2)}=0.033$ ), which suggests developmental mortality among offspring sharing host resources. Because developmental mortality may be sex-specific, we compared the distribution of offspring sexes in gregarious mummies with their binomial expectations, using the mean sex ratio of singly developing offspring $(\mathrm{p}=0.378 ; \mathrm{n}=$ 1233 ) as a control and pooling the data between experiments 1-4 for a larger sample size. The four experiments yielded a total of 24 gregarious mummies, with two male offspring, one male plus one female offspring, and two female offspring emerging from 15,3 and 6 mummies, respectively. Mummies yielding two male offspring exceeded their binomial expectations whereas the two other mummy classes were underrepresented $\left(\mathrm{G}_{\mathrm{adj}}=31.96\right.$; d.f. $=2 ; P<0.001)$.

\section{Sex ratio}

The offspring sex ratio produced by mated mothers (experiments 1-4) was female-biased (Fisher's test for combining probabilities from separate tests of significance, $\mathrm{X}^{2}$ $=27.034$; d.f. $=8 ; P<0.001)($ Table 1$)$. The degree of bias was least among the offspring of singly-caged females provided with 12 mummies for $2 \mathrm{~h}$ (experiment 1 ), with a mean sex ratio of $\mathrm{p}_{\mathrm{N}}=0.433$. This ratio was not significant- 
ly different from the mean sex ratio of $\mathrm{p}_{\mathrm{N}}=0.430$ produced by two mated females caged together for $1 \mathrm{~h}$ (experiment 2). The proportion of daughters among surviving offspring increased the longer two females competed for a constant host supply (1-way ANOVA: $\mathrm{F}_{3,132}=6.202 ; P<0.001$ ) (Table 1).

In experiment 5 , one mated female caged together with one unmated female for $1 \mathrm{~h}$ produced a mean cohort sex ratio of $\mathrm{p}_{\mathrm{N}}=0.645(95 \% \mathrm{CI}=0.585-0.701 ; \mathrm{n}=257)$. If both females contribute equal numbers of offspring (assumption 4) and mated females do not adjust their offspring sex allocation behaviour $\left(\mathrm{p}_{\mathrm{N}}=0.433\right.$; experiment 1$)$ in the presence of a potential competitor, equation 2 predicts a cohort sex ratio of $\mathrm{p}_{\mathrm{N}}=0.5 \cdot(1+0.433)=0.717$, which is indicated by the asterisk in Fig. 2. The difference between the observed cohort sex ratio and the one predicted could have been due to mated females either laying relatively more fertilized eggs (i.e., $p_{B}<0.433$ ) or contributing relatively more offspring to the total (i.e., $[1-\mathrm{r}]>0.5$ ) without changing offspring sex allocation, or a combination of both. For example, for $r=0.5$, a mated female would have to produce ca. $25 \%$ more daughters in the presence of an unmated competitor to yield a cohort sex ratio of $\mathrm{p}_{\mathrm{N}}=$ 0.645 if immature mortality is random with regard to sex.

The cohort sex ratio produced by isolated mated females showed considerable variation $(\mathrm{CV}=30.4 \%)$ in experiment 1; however, the sex ratio was not correlated with cohort size (Kendall's tau $\left.=-0.014 ; P_{\alpha(2)}=0.90 ; \mathrm{n}=46\right)$ (Fig. $3)$. The results were similar when two mated females were caged together for $1 \mathrm{~h}$ (Kendall's $\operatorname{tau}=-0.129 ; P_{\alpha(2)}=0.36$; $\mathrm{n}=30), 2 \mathrm{~h}(0.276 ; 0.06 ; 30)$ and $3 \mathrm{~h}(0.102 ; 0.50 ; 30)$.

\section{DISCUSSION}

We have shown that mated females of the solitary ectoparasitoid $D$. carpenteri produce more daughters when competing for hosts with conspecific females searching the same patch. The number of offspring produced per female did not vary between singly-caged mated females and two mated females or one mated and one unmated female caged together under the same host constraints. However, the distribution of eggs over available hosts was influenced by the number of females present in the patch. Single females laid relatively fewer eggs per host and rarely selfsuperparasitized. In contrast, an increasing proportion of mummies was superparasitized with two and occasionally three eggs when two females were caged together (Table 1; Fig. 1). Because females could revisit an already parasitized mummy and lay additional eggs, superparasitism may simply be the result of females randomly "dumping" eggs when confined with a diminishing host supply. Females of $D$. carpenteri can store an average of 15-20 eggs in their ovaries but are unable to resorb eggs (Le Ralec, 1991); thus, any eggs not laid will decline in value when few suitable hosts are found. We cannot exclude that "egg dumping" contributed to increased superparasitism and, in fact, may account for the low level of self-superparasitism by isolated females observed in experiment 1; however, its overall importance was probably negligible. Alternatively, a female with a large supply of eggs may change her oviposition behaviour if she detects the presence of a conspecific competitor in the same patch or encounters parasitized mummies. Females of $D$. carpenteri invest several minutes in examining mummies prior to oviposition (Chow \& Mackauer, 1999b). This investment in time and effort will be lost if a mummy is rejected or, if accepted, offspring do not survive. However, a female can gain fitness by depositing more than one egg per host if the probability of one of her own offspring surviving larval competition increases with clutch size (Visser et al., 1990, 1992; Mackauer et al., 1992). Moreover, Mackauer \& Chow (2015) found that larvae of $D$. carpenteri are facultatively gregarious, with two and occasionally three offspring successfully developing on a superparasitized host.

The sex ratio of $D$. carpenteri shows a moderate femalebias in natural populations (Höller, 1988; Mackauer \& Lardner, 1995). In our experiments, singly-caged females produced slightly more daughters than sons, which agrees with the sex ratio observed in the field. In contrast, the proportion of daughters among the offspring produced by two mated females competing for hosts increased with the period of confinement and superparasitism (Table 1). Sex ratio bias is commonly observed when several females compete for hosts (King, 1993; Godfray, 1994; West, 2009; Ito \& Yamada, 2016). The proximate causes of such bias often differ or may not be altogether clear. For example, King $\&$ Seidl (1993) reported that females of Muscidifurax raptor Girault \& Sanders (Hymenoptera: Pteromalidae) produced relatively more sons in the presence of a conspecific female than when alone although this change was not consistent. In the gregarious Bracon hebetor Say (Hymenoptera: Braconidae), Galloway \& Grant (1989) observed a sex-ratio shift towards more female progeny on superparasitized hosts. In contrast, Antolin et al. (1995) showed that some females of $B$. hebetor are ovicidal and produce a balanced or a male-biased sex ratio by killing the mainly female eggs, which are laid first when in competition with conspecifics.

Because we could not distinguish between the offspring of a first- and a second-attacking (i.e., superparasitizing) female of $D$. carpenteri, we used an algebraic model to estimate the primary sex ratio at oviposition and any changes in the sex-allocation behaviour when two females compete for hosts, with one female being mated and the other unmated. Importantly, we did not control the encounter sequence of different females. Mated and unmated females were equally likely to encounter an unparasitized host and deposit an egg as well as to re-encounter and reject or, alternatively, accept and superparasitize an already parasitized host. Whereas both kinds of female can alter their offspring allocation in response to patch experience (van den Assem, 1971; Charnov et al., 1981; Suzuki et al., 1984; Visser et al., 1990; Cloutier et al., 1991), only mated females can alter offspring sex allocation in response to parasitized and unparasitized hosts. For example, after encountering an already parasitized host or a conspecific competitor, a female may place a higher value on the next host she finds 
and deposit a fertilized rather than an unfertilized egg regardless of host quality and oviposition sequence (Chow \& Mackauer, 1996).

Sex ratio bias can also be caused by asymmetric offspring mortality in superparasitized hosts if one sex is a superior competitor or requires relatively fewer host resources than the other. Male larvae are competitively superior to female larvae in Trichogramma chilonis Ishii and T. evanescens Westwood (Hymenoptera: Trichogrammatidae), two gregarious egg parasitoids (Suzuki et al., 1984; van Dijken \& Waage, 1987). In contrast, immature mortality is less for female than male larvae in A. victus (van Baaren et al., 1999). In D. carpenteri, males require less time and fewer resources for development than females (Otto \& Mackauer, 1998). Therefore, males will do relatively better when resources are limiting in superparasitized hosts, which agrees with the greater than predicted proportion of gregarious mummies from which two males emerged in our experiments. But a hypothetical male advantage in immature survival should cause the sex ratio at emergence to become relatively more male-biased, which is opposite the direction observed by us.

Our experiments were not designed to identify the proximate causes of the increased female-bias in the cohort sex ratio; however, certain inferences are possible. First, we can exclude that the increased superparasitism was caused by the absence of suitable hosts because females superparasitized even when unparasitized mummies were available (Fig. 1). Second, we can exclude that superparasitism was influenced by pre-experiment experience. All mated females were kept in groups together with other males and females prior to their use; however, singly-caged females rarely self-superparasitized (Table 1). Third, we can exclude that mated females contributed relatively more offspring without a change in offspring sex allocation. Although cohort size increased under competition, the fact that the cohort sex ratio was not correlated with cohort size argues against this explanation (Fig. 3). The fourth and most likely explanation is that mated females changed their offspring sex-allocation behaviour and fertilized more eggs at oviposition when detecting a conspecific competitor in the same patch. The presence of conspecific females searching the same patch, or of already parasitized mummies, indicates to a female that the survival of her own offspring may be at risk if the host is superparasitized by a competitor. Under both scenarios, any unparasitized mummy that a mated female can find will increase in value and should be accepted for oviposition with a fertilized egg, regardless of its quality. In conclusion, a strategy of depositing more fertilized eggs, rather than alternating between fertilized and unfertilized eggs, allows a mated female of $D$. carpenteri to increase the proportion of her daughters among parasitoids competing for a diminishing host supply. Even if unable to mate herself, a daughter surviving larval competition can disperse and produce grandsons that can find a mate in the following generation when more hosts may be available, whereas sons must find a mate and have offspring in the current generation to gain fitness. Studies of the population mating structure and patch-residence times of males and females of $D$. carpenteri are needed to test this hypothesis.

ACKNOWLEDGEMENTS. We thank the Natural Sciences and Engineering Research Council of Canada for financial support.

\section{REFERENCES}

Agresti A. \& Coull B.A. 1998: Approximate is better than "exact" for interval estimation of binomial proportions. - Am. Stat. 52: 119-126.

Antolin M.F., Ode P.J. \& Strand M.R. 1995: Variable sex ratios and ovicide in an outbreeding parasitic wasp. - Anim. Behav. 49: 589-600.

Bocchino F.J. \& Sullivan D.J. 1981: Effects of venoms from two aphid hyperparasitoids, Asaphes lucens and Dendrocerus carpenteri (Hymenoptera: Pteromalidae and Megaspilidae), on larvae of Aphidius smithi (Hymenoptera: Aphidiidae). - Can. Entomol. 113: 887-889.

Brodeur J. \& Boivin G. 2004: Functional ecology of immature parasitoids. - Annu. Rev. Entomol. 49: 27-49.

Charnov E.L., Los-den-Hartog R.L., Jones W.T. \& van Den Assem J. 1981: Sex ratio evolution in a variable environment. - Nature (London) 289: 27-33.

CHow A. 2000: Influence of host distribution on foraging behaviour in the hyperparasitoid wasp, Dendrocerus carpenteri. Entomol. Exp. Appl. 97: 57-66.

Chow A. \& MackAuer M. 1996: Sequential allocation of offspring sexes in the hyperparasitoid wasp, Dendrocerus carpenteri. - Anim. Behav. 51: 859-870.

Chow A. \& Mackauer M. 1999a: Marking the package or its contents: host discrimination and acceptance in the ectoparasitoid Dendrocerus carpenteri (Hymenoptera: Megaspilidae). - Can. Entomol. 131: 495-505.

Chow A. \& Mackauer M. 1999b: Host handling and specificity of the hyperparasitoid wasp, Dendrocerus carpenteri (Curtis) (Hym., Megaspilidae): importance of host age and species. J. Appl. Entomol. 123: 83-91.

Cloutier C., Lévesque A., Eaves D.M \& Mackauer M. 1991: Maternal adjustment of sex ratio in response to host size in the aphid parasitoid Ephedrus californicus. - Can. J. Zool. 69: 1489-1495.

Darrouzet E., Imbert E. \& Chevrier C. 2003: Self-superparasitism consequences for offspring sex ratio in the solitary ectoparasitoid Eupelmus vuilleti. - Entomol. Exp. Appl. 109: 167-171.

Darrouzet E., Boivin G. \& Chevrier C. 2008: Sex allocation decision under superparasitism by the parasitoid wasp Eupelmus vuilleti. - J. Insect Behav. 21: 181-191.

Diaz-Fleischer F., Galvez C. \& Montoya P. 2015: Oviposition, superparasitism, and egg load in the solitary parasitoid Diachasmimorpha longicaudata (Hymenoptera: Braconidae): response to host availability. - Ann. Entomol. Soc. Am. 108: 231-241.

Dorn S. \& BeCKAGE N.E. 2007: Superparasitism in gregarious hymenopteran parasitoids: ecological, behavioural and physiological perspectives. - Physiol. Entomol. 32: 199-211.

Ellers J., BaX M. \& van Alphen J.J.M. 2001: Seasonal changes in female size and its relation to reproduction in the parasitoid Asobara tabida. - Oikos 92: 309-314.

Galloway K.S. \& GRant B. 1989: Reverse sex-ratio adjustment in an apparently outbreeding wasp, Bracon hebetor. - Evolution 43: 465-468. 
Godfray H.C.J. 1994: Parasitoids: Behavioral and Evolutionary Ecology. Princeton University Press, Princeton, NJ, 473 pp.

Gu H., WAng Q. \& Dorn S. 2003: Superparasitism in Cotesia glomerata: response of hosts and consequences for parasitoids. - Ecol. Entomol. 28: 422-431.

Harvey J.A., Poelman E.H. \& Tanaka T. 2013: Intrinsic interand intraspecific competition in parasitoid wasps. - Annu. Rev. Entomol. 58: 333-351.

HöLlER C. 1988: Effizienzanalyse der Parasitoiden an Getreideblattläusen. PhD Thesis, Christian-Albrechts-Universität, Kiel, $114 \mathrm{pp}$.

Iто E. \& Yamada Y.Y. 2014: Self- / conspecific discrimination and superparasitism strategy in the ovicidal parasitoid Ech throdelphax fairchildii (Hymenoptera: Dryinidae). — Insect Sci. 21: 741-749.

Iтo E. \& Yamada Y.Y. 2016: Presence of a conspecific increases superparasitism but not infanticide under self- and conspecific superparasitism in a semisolitary parasitoid, Echthrodelphax fairchildii (Hymenoptera: Dryinidae). - Entomol. Sci. 19: 25-33.

Kapranas A., Hardy I.C.W., Morse J.G. \& LuCK R.F. 2011: Parasitoid developmental mortality in the field: patterns, causes and consequences for sex ratio and virginity. - J. Anim. Ecol. 80: 192-203.

KING B.H. 1993: Sex ratio manipulation by parasitoid wasps. In Wrensch D.L. \& Ebbert M.A. (eds): Evolution and Diversity of Sex Ratio in Insects and Mites. Chapman and Hall, New York and London, pp. 418-441.

King B.H. \& SEIDL S.E. 1993: Sex ratio response of the parasitoid wasp Muscidifurax raptor to other females. - Oecologia 94: 428-441.

Lebreton S., Chevrier C. \& Darrouzet E. 2010: Sex allocation strategies in response to conspecifics' offspring sex ratio in solitary parasitoids. - Behav. Ecol. 21: 107-112.

Le Ralec A. 1991: Les Hyménoptères Parasitoides: Adaptations de l'Appareil Reproducteur Femelle. Morphologie et Ultrastructure de l'Ovaire, de l'Oeuf et de l'Ovipositeur. PhD Thesis, Université de Rennes I, Rennes, 117 pp.

MACKAUER M. 1990: Host discrimination and larval competition in solitary endoparasitoids. In Mackauer M., Ehler L.E. \& Roland J. (eds): Critical Issues in Biological Control. Intercept, Andover, Hants, pp. 41-62.

Mackauer M. \& ChOw A. 2015: Facultative gregarious development in a solitary parasitoid wasp, Dendrocerus carpenteri: larvae may share nutritional resources. - Entomol. Exp. Appl. 157: $170-180$.

MACKAUER M. \& CHOw F.J. 2012: Facultative gregarious development in a solitary koinobiont parasitoid, Ephedrus californicus: implications of larval ecology and host constraints. - Entomol. Exp. Appl. 142: 203-210.

MACKAUER M. \& LARDNER R.M. 1995: Sex-ratio bias in an aphid parasitoid-hyperparasitoid association: a test of two hypotheses. - Ecol. Entomol. 20: 118-124.

Mackauer M., Bai B., Chow A. \& DanyK T. 1992: Asymmetric larval competition between two species of solitary parasitoid wasps: the influence of superparasitism. - Ecol. Entomol. 17: 233-236.

Mackauer M., Michaud J.P. \& VöLKL W. 1996: Host choice by aphidiid parasitoids (Hymenoptera: Aphidiidae): host recognition, host quality, and host value. - Can. Entomol. 128: 959-980.

Mackauer M., Sequeira R. \& Otto M. 1997: Growth and development in parasitoid wasps: adaptation to variable host resources. In Dettner K., Bauer G. \& Völkl W. (eds): Vertical
Food Web Interactions: Evolutionary Patterns and Driving Forces. Springer, Berlin, pp. 191-203.

MAYHEW P.J. \& VAN AlPHEN J.J.M. 1999: Gregarious development in alysiine parasitoids evolved through a reduction in larval aggression. - Anim. Behav. 58: 131-141.

Montoya P., Cancino J., Perez-Lachaud G. \& Liedo P. 2011: Host size, superparasitism and sex ratio in mass-reared Diachasmimorpha longicaudata, a fruit fly parasitoid. - BioControl 56: 11-17.

Montoya P., Ruiz L., Cancino J. \& Liedo P. 2013: Field superparasitism by Diachasmimorpha longicaudata attacking Anastrepha spp. larvae on mango fruits. - Biol. Contr. 64: 160-165.

Nostvik E. 1954: Biological studies of Pachycrepoideus dubius Ashmead (Chalcidoidea: Pteromalidae), a pupal parasite of various Diptera. - Oikos 5: 195-204.

Ode P.J., Antolin M.F. \& Strand M.R. 1996: Sex allocation and sexual asymmetries in intra-brood competition in the parasitic wasp Bracon hebetor. - J. Anim. Ecol. 65: 690-700.

Отto M. \& Mackauer M. 1998: The developmental strategy of an idiobiont ectoparasitoid, Dendrocerus carpenteri: influence of variations in host quality on offspring growth and fitness. Oecologia 117: 353-364.

RIDDICK E.W. 2002: Superparasitism occasionally predisposes Cotesia marginiventris (Cresson) (Hymenoptera: Braconidae) to develop gregariously in Spodoptera exigua (Hübner) (Lepidoptera: Noctuidae). - J. Entomol. Sci. 37: 1-9.

Rózsa L., Reiczigel J. \& Majoros G. 2000: Quantifying parasites in samples of hosts. - J. Parasitol. 86: 228-232.

Shuker D.M., Pen I., Duncan A.B., Reece S.E. \& West S.A. 2005: Sex ratios under asymmetrical local mate competition: theory and a test with parasitoid wasps. - Am. Nat. 166: 301316.

Sokal R.R. \& Rohlf F.J. 1995: Biometry. 3rd ed. W.H. Freeman, New York, $887 \mathrm{pp}$.

SUZUKI Y. \& IWASA Y. 1980: A sex ratio theory of gregarious parasitoids. - Res. Popul. Ecol. 22: 366-382.

SuZuKi Y., TsujI H. \& SASAKaWA M. 1984: Sex allocation and effects of superparasitism on secondary sex ratios in the gregarious parasitoid, Trichogramma chilonis (Hymenoptera: Trichogrammatidae). - Anim. Behav. 32: 478-484.

Sykes E.M., Innocent T.M., Pen I., Shuker D.M. \& West S.A. 2007: Asymmetric larval competition in the parasitoid wasp Nasonia vitripennis: a role in sex allocation? - Behav. Ecol. Sociobiol. 61: 1751-1758.

Tena A., Kapranas A., Garcia-Mari F. \& Luck R.F. 2009: Larval cannibalism during the late developmental stages of a facultatively gregarious encyrtid endoparasitoid. - Ecol. Entomol. 34: 669-676.

Tena A., Kapranas A., Walker G.P., Garcia-Mari F. \& Luck R.F. 2011: Larval morphology of Metaphycus flavus and its role in host attachment and larval cannibalism. - Bull. Entomol. Res. 101: 365-372.

VAN AlPHen J.J.M. \& VisSER M.E. 1990: Superparasitism as an adaptive strategy for insect parasitoids. - Annu. Rev. Entomol. 35: $59-79$.

VAN BAARen J., LANDRY B.L. \& BoIvin G. 1999: Sex allocation and larval competition in a superparasitizing solitary egg parasitoid: competing strategies for an optimal sex ratio. - Funct. Ecol. 13: 66-71.

VAN DEN AsSEm J. 1971: Some experiments on sex ratio and sex regulation in the pteromalid Lariophagus distinguendus. Neth. J. Zool. 21: 373-402.

van DiJKen M.J. \& WAage J.K. 1987: Self and conspecific superparasitism by the egg parasitoid Trichogramma evanescens. Entomol. Exp. Appl. 43: 183-192. 
VISSER M.E. 1995: The effect of competition on oviposition decisions of Leptopilina heterotoma (Hymenoptera: Eucoilidae). - Anim. Behav. 49: 1677-1687.

Visser M.E., van AlPhen J.J.M. \& Nell H.W. 1990: Adaptive superparasitism and patch time allocation in solitary parasitoids: the influence of the number of parasitoids depleting a patch. Behaviour 114: 21-36.

Visser M.E., Luyckx B., Nell H.W. \& Boskamp G.J.F. 1992: Adaptive superparasitism in solitary parasitoids: marking of parasitized hosts in relation to the pay-off from superparasitism. - Ecol. Entomol. 17: 76-82.

WALKer G.P. \& CAMERON P.J. 1981: The biology of Dendrocerus carpenteri (Hymenoptera: Ceraphronidae), a parasite of Aphidius species, and field observations of Dendrocerus species as hyperparasites of Acyrthosiphon species. - N. Z. J. Zool. 8: $531-538$
WERREN J.H. 1984: Brood size and sex ratio regulation in the parasitic wasp Nasonia vitripennis (Walker) (Hymenoptera: Pteromalidae). - Netherl. J. Zool. 34: 123-143.

WESSA P. 2012: Free Statistics Software. Ver. 1.1.23-r7. Office for Research Development and Education, URL: http://www. wessa.net/rwasp_kendall.wasp/

West S.A. 2009: Sex Allocation. Princeton University Press, Princeton, NJ, and Oxford, $468 \mathrm{pp}$.

WyLIE H.G. 1965: Effects of superparasitism on Nasonia vitripennis (Walk.) (Hymenoptera: Pteromalidae). - Can. Entomol. 97: 326-331.

WYLIE H.G. 1979: Sex ratio variability of Muscidifurax zaraptor (Hymenoptera: Pteromalidae). - Can. Entomol. 111: 105-109.

Received July 25, 2016; revised and accepted September 20, 2016 Published online November 8, 2016 